\title{
Spitz nevi and atypical Spitz nevi/tumors: a histologic and immunohistochemical analysis
}

\author{
Payal Kapur ${ }^{1}$, M Angelica Selim², Lonnie C Roy ${ }^{3}$, Mani Yegappan ${ }^{1}$, Arthur G Weinberg ${ }^{1,3}$ \\ and Mai P Hoang ${ }^{1,3}$
}

${ }^{1}$ Department of Pathology, University of Texas Southwestern Medical Center, Dallas, TX, USA; ${ }^{2}$ Duke University Medical Center, Durham, NC, USA and ${ }^{3}$ Children's Medical Center, Dallas, TX, USA

\begin{abstract}
A subset of Spitz nevi poses substantial diagnostic difficulty, even among experts, due to its resemblance to malignant melanoma. These lesions are termed atypical Spitz nevi/tumors and there is currently a lack of objective criteria for predicting their biologic behavior. We compared the expression of Ki-67, p21, and fatty acid synthase by immunohistochemistry in 10 atypical Spitz nevi, 28 typical Spitz nevi, 19 compound melanocytic nevi and 18 invasive malignant melanomas. There was a progressive increase in fatty acid synthase cytoplasmic expression with statistically significant differences observed between Spitz nevi and atypical Spitz nevi $(P=0.003)$ and between atypical Spitz nevi and malignant melanoma $(P<0.050)$. Ki-67 nuclear staining was lower in both typical and atypical forms of Spitz lesions than in malignant melanoma $(P<0.001)$. The degree of P21 nuclear expression in atypical Spitz nevi was not significantly different than in Spitz nevi, but was significantly greater than expression in conventional nevi and approached significance after multiple comparisons corrections for malignant melanoma. Thus, a high level of P21 expression makes a tumor more likely to be a typical or atypical Spitz nevus than a malignant melanoma, especially when coupled with a low $\mathrm{Ki}-67$ index and weak expression of fatty acid synthase. These immunohistochemical observations support the concept that atypical Spitz nevi are distinct lesions of borderline biologic behavior residing between Spitz nevi and malignant melanoma. The study also compared a large array of histologic features of 16 cases of typical Spitz nevi in children with $\mathbf{1 2}$ typical Spitz nevi in adults. The adult lesions were significantly more likely to be intradermal and to display dermal fibroplasia, but were histologically similar to their pediatric counterparts in all other respects.
\end{abstract}

Modern Pathology (2005) 18, 197-204, advance online publication, 1 October 2004; doi:10.1038/modpathol.3800281

Keywords: Spitz nevi; spindle and epithelioid cell nevus; atypical Spitz nevi/tumors; p21; Ki-67; fatty acid synthase; immunohistochemistry

Characterized in late 1948 by Sophie Spitz as 'juvenile melanomas', Spitz (spindle and epithelioid cell) nevi are now recognized as a distinct entity. ${ }^{1} \mathrm{~A}$ subset of Spitz nevi poses substantial diagnostic difficulties, even among experts, due to its resemblance to malignant melanoma and such cases are termed atypical Spitz nevi/tumors., ${ }^{2,3}$ Currently, there is a lack of objective criteria for predicting the biologic behavior of such lesions. ${ }^{3,4}$ Some studies have suggested the following histologic criteria for assessing the malignant potential of Spitz nevi: large size $(>1.0 \mathrm{~cm})$, tumor extension into the subcutis, presence of ulceration, and high

Correspondence: Dr MP Hoang, MD, Department of Pathology, University of Texas Southwestern Medical Center, 5323 Harry Hines Blvd, Dallas, TX 75390-9073, USA.

E-mail: mai.hoang@UTSouthwestern.edu

Received 29 June 2004; revised 5 August 2004; accepted 6 August 2004; published online 1 October 2004 mitotic index. ${ }^{5,6}$ However, these studies focused mainly on the clinical and histologic features without consideration of the immunohistochemical profile.

Many studies have investigated the role of immunohistochemical stains in distinguishing Spitz nevi from malignant melanoma, but no markers are yet known to reliably differentiate the two neoplasms. Bergman et $\mathrm{al}^{7}$ reported that Spitz nevi show a stratified staining pattern for HMB-45, but Palazzo and Duray ${ }^{8}$ and Smith et $a l^{9}$ found a heterogeneous HMB-45 staining pattern in typical Spitz nevi. There is overlap in the staining pattern of AgNOR (silver-stained nucleolar organizing region) that is not helpful in distinguishing Spitz nevi from malignant melanoma. ${ }^{10,11}$ Similar results are observed for DNA ploidy analysis, cyclin D1, c-myc, $\mathrm{c}$-fos, telomerase, and Bcl-2. ${ }^{12-17}$ Negligible levels of p53 expression are seen in Spitz nevi in contrast with higher expression in malignant melanoma. ${ }^{18}$ 
However, a negative result does not exclude malignant melanoma since positive p53 staining is reported in only $35 \%$ of malignant melanomas. ${ }^{19}$ Loss of p16 expression is documented in both melanocytic nevi and malignant melanomas. ${ }^{20}$

Ki-67 protein (MIB-1) is expressed during the proliferative cell cycle (G1, S, G2, and M phases) and is absent in the resting (G0) phase. ${ }^{21}$ Several studies have shown that the MIB-1 index is a helpful marker for distinguishing between melanocytic nevi and malignant melanoma. ${ }^{8,16,17,20,22}$ Tumor suppressor $p 21^{\mathrm{WAF} 1 / \mathrm{CIP} 1}$ is the main downstream effector gene mediating p53-induced cell cycle arrest and has different expression in nevi and malignant melanoma. ${ }^{20}$ Fatty acid synthase, the key enzyme responsible for the synthesis of fatty acids, was weakly expressed in some normal human tissues. Recently, strong expression of fatty acid synthase was found in malignant melanoma, while only weak expression was present in melanocytic nevi. ${ }^{23}$ In this study, we investigated the potential use of Ki-67, p21, and fatty acid synthase immunohistochemical stains for distinguishing atypical pediatric Spitz nevi from malignant melanoma. In addition, we compared a broad array of histologic features in typical pediatric Spitz nevi to typical Spitz nevi in adults.

\section{Materials and methods}

The study was approved by the internal review boards at University of Texas Southwestern Medical Center at Dallas (IRB\# 0103-070) and Duke University Medical Center. Archival materials of 28 cases of typical Spitz nevi of either intradermal or compound type (16 in pediatric patients, 12 in adults), 19 cases of conventional compound melanocytic nevi (nine in pediatric patients, 10 in adults), eight atypical pediatric Spitz nevi, and 18 cases of adult invasive malignant melanoma (Breslow thickness greater than $1.0 \mathrm{~mm}$ ) diagnosed in 1993-2003 were retrieved from the pathology files of the University of Texas Southwestern Medical Center and Children's Medical Center at Dallas. Two additional atypical pediatric Spitz nevi were obtained from the pathology files of Duke University Medical Center, Durham, North Carolina. Tumor thickness of the atypical pediatric Spitz nevi ranged from 2.0 to $9.2 \mathrm{~mm}$. For this reason, only melanoma cases with a Breslow thickness greater than $1.0 \mathrm{~mm}$ were selected for the study (median: $3.75 \mathrm{~mm}$, mean: $5.49 \mathrm{~mm}$, range: $1.23-19 \mathrm{~mm}$ ). Clinical information was obtained from medical records.

\section{Histologic Evaluation of Spitz Nevi}

The following architectural and cytologic features were graded as either present or absent in Spitz nevi and atypical Spitz nevi: type (intradermal or compound), symmetry, circumscription, lateral extension/shoulder, single-cell pattern, suprabasal spread, disordered junctional nesting, expansile nodule, increased cellularity, uniformity of nests, predominance of either spindle or epithelioid cell, loss of cellular cohesion, deep extension into subcutaneous tissue, maturation, ulceration, necrosis, dermal fibroplasia, nuclear pleomorphism, variation in nuclear chromatin, nuclear enlargement, variation in nucleoli, mitotic figures, atypical mitotic figures, and marginal mitotic figures. The mitotic figures were the sum for 10 high-power fields (HPF). The inflammatory infiltrate was graded as mild $(+)$, moderate $(++)$, or marked $(+++)$. The size and depth of the tumors were measured in millimeters.

Criteria used for diagnosing atypical Spitz nevi were those outlined by Barnhill. ${ }^{24}$ These features included asymmetry, expansile nodule, increased cellularity, deep extension into subcutaneous tissue, lack of maturation, nuclear pleomorphism, and marginal mitoses. All 10 atypical Spitz nevi/tumors had three or more of these features.

\section{Immunohistochemistry}

Sections ( $4 \mu \mathrm{m}$ thick) were obtained for immunohistochemical studies, which were performed using standard avidin-biotin peroxidase complex techniques, heat-induced epitope retrieval buffer, biotin blocking system, and primary antibody against Ki-67 (clone MIB-1, 1:150, Dako, Carpinteria, CA, USA), p21 ${ }^{\text {WAF1/CIP1 }}$ (clone SX118, 1:25, Dako), and fatty acid synthase (clone 14G5, $3 \mu \mathrm{g} / \mathrm{ml}$, Immuno-Biological Laboratories Co., Ltd., Japan). p21 immunostain was repeated on a number of selected cases (two nevi, two Spitz nevi, four atypical Spitz nevi, two melanomas) with another monoclonal antibody (clone SX118, 1:20, BD Biosciences Pharmingen, San Diego, CA, USA) that has already been standardized by UT Southwestern Laboratory of Immunohistochemistry. Appropriate negative and positive controls were included with each run. For fatty acid synthase staining, its expression in sebaceous glands and stratum granulosum of the epidermis was used as internal positive control, in accordance with the recent work of Uchiyama et $a .^{25}$ The sections were lightly counterstained by the Giemsa method so that unstained nuclei were light blue in color and any melanin pigment appeared green. ${ }^{26}$

Each case was scored separately by two of the authors in a blinded fashion (PK and MPH). The cases, for which there was disagreement, were rescored jointly for consensus. Ki-67 and p21 immunoreactivity was scored as a percentage on the basis of a manual 500-cell count in the most densely staining area at the junction of the epidermis and dermis, and in the dermis. Evaluation of fatty acid synthase expression was performed using a combined scoring system based on both the fraction of positive tumor cells and the predominant 
staining intensity in the tumor similar to that outlined by Innocenzi et $a .^{23}$ The number of positive cells was graded using a three-tiered scale $(<10 \%=0,11-50 \%=1,51-80 \%=2,>80 \%=3)$. The staining intensity was scored on a three-tiered scale (negative: 0, low intensity: 1, moderate intensity: 2, and strong intensity: 3). The overall score in each case was the average of the staining intensity and positive fraction score.

\section{Statistical Analysis}

Comparison of the percentages of positive Ki-67 and p21 nuclear staining and fatty acid synthase expression of the four groups (conventional nevi, Spitz nevi, atypical Spitz nevi, and malignant melanoma) was performed by the Kruskal-Wallis nonparametric analysis of variance because of their non-normal distributions. Dunn-Sidak post hoc corrections were used for the multiple pair-wise comparisons. The discriminating ability of p21 positivity (sensitivity, specificity) to distinguish between Spitz nevi and malignant melanoma was further evaluated using the area under the receiver operating characteristic (ROC) curve. Two-tailed $P$-values of less than 0.05 were considered to be statistically significant.

\section{Results}

\section{Demographic Data}

The age of the patients with atypical pediatric Spitz nevi ranged from 6 months to 10 years (mean, 4 years; median, 3 years). The female to male ratio was $4: 1$. The anatomic location of the tumors was: lower extremity (4); upper extremity (2); head and neck (3); and trunk (1). The clinical impression for all was benign and included nevus, Spitz nevus, blue nevus, hemangioma, and pyogenic granuloma. A re-excision was performed in three patients. Of these three patients, one also had a sentinel lymph node dissection and one had a regional lymph node dissection. None of these specimens demonstrated either residual or metastatic tumor. All 10 patients are alive and without evidence of disease with follow-up ranging from 1 to 9 years (median, 4.5 years; mean, 4.6 years).

The age of the patients with typical pediatric Spitz nevi ranged from 2 to 14 years (mean, 6 years; median, 5.5 years). The female to male ratio was 1:1. The anatomic location of the tumors was: lower extremity (2); upper extremity (4); head and neck (8); trunk (1); and not specified (1). All 16 patients are alive and without evidence of disease with follow-up ranging from 1 to 10 years (median, 4.75 years; mean, 4.5 years).

The age of the patients with adult typical Spitz nevi ranged from 21 to 47 years (mean, 34 years; median, 30 years). The female to male ratio was 1:1.
The anatomic location of the tumors was: lower extremity (7); head and neck (1); and trunk (4). All 12 patients are alive and without evidence of disease with follow-up ranging from 1 to 11 years (median, 3 years; mean, 4 years).

The age of the patients with malignant melanomas ranged from 35 to 97 years (mean, 67 years; median, 65.5 years). The female to male ratio was $1: 7$. The anatomic location of the tumors was: upper extremity (1); lower extremity (4); head and neck (7); and trunk (6).

\section{Histologic Evaluation}

Histologic features of the 28 typical Spitz nevi (12 adult and 16 children) and 10 atypical pediatric Spitz nevi are summarized in Table 1 . The only statistical significance differences $(P<0.05)$ observed between the adult and pediatric cases of typical Spitz nevi were nevus type (compound in children, intradermal in adults) and greater proportion dermal fibroplasia in the adult cases.

An expansile nodular growth was present in nine of 10 atypical Spitz nevi (Figure 1a). Six of these tumors extended to the subcutaneous tissue (Figure 1b). Lateral extension was seen in six of eight compound tumors (Figure 1c). The predominant morphology was spindle in nine (Figure 1d) and epithelioid in one (Figure 1e). All but one had mitotic figures in dermal melanocytes (1-6/10HPF). Atypical mitotic figures were present in all but one case (Figure 1f). Marginal mitoses were seen in three cases. Based upon criteria established by Spatz et $a l,{ }^{5}$ eight cases were low-risk, one intermediaterisk and one high-risk.

\section{Immunohistochemistry}

Mean Ki-67, p21, and fatty acid synthase counts in conventional nevi, Spitz nevi, atypical Spitz nevi, and malignant melanomas are presented in Table 2. Nuclear positivity was noted for Ki-67 and p21 while cytoplasmic reactivity was seen for fatty acid synthase (Figure 2). These data are presented as box plots in Figures 3, 4, and 6. The omnibus KruskalWallis analysis of variance tests indicated that at least two of the four groups had significantly different median Ki-67, p21, and fatty acid synthase expression levels. Post hoc pairwise comparisons indicated that there was a progressive increase in Ki-67 nuclear staining from conventional nevi to malignant melanoma with statistical significance observed between each group (Figure 3). However, there was some overlap in the distributions between Spitz nevi and melanoma at lower levels of Ki-67 activity. p21 expression was not significantly different in Spitz nevi and atypical Spitz nevi, but was significantly higher than in conventional nevi and approached being significantly higher for malignant melanoma, after correcting for multiple comparisons 
Table 1 Summary of histologic features of Spitz nevi and atypical Spitz nevi/tumors

\begin{tabular}{|c|c|c|c|}
\hline Histologic features & Children (\%) & Adults (\%) & Atypical (\%) \\
\hline Intradermal type & $6 / 16(38)$ & $11 / 12(92)$ & $2 / 10(20)$ \\
\hline Compound type & $10 / 16(62)$ & $1 / 12(8)$ & $8 / 10(80)$ \\
\hline Asymmetry & $1 / 16(6)$ & $0 / 12(0)$ & $5 / 10(50)$ \\
\hline Poor circumscription & $0 / 12(0)$ & $0 / 12(0)$ & $3 / 10(30)$ \\
\hline Lateral extension/shoulder & $1 / 10(10)$ & $0 / 1(0)$ & $6 / 8(75)$ \\
\hline Single-cell pattern & $6 / 10(60)$ & $5 / 12(42)$ & $2 / 8(25)$ \\
\hline Suprabasal melanocytes & $7 / 10(70)$ & $0 / 1(0)$ & $4 / 8(50)$ \\
\hline Disordered junctional nesting & $1 / 10(10)$ & $0 / 1(0)$ & $4 / 8(50)$ \\
\hline Expansile nodule & $0 / 16(0)$ & $1 / 12(8)$ & $9 / 10(90)$ \\
\hline Increased cellularity & $0 / 16(0)$ & $0 / 12(0)$ & $7 / 10(70)$ \\
\hline Uniformity of nests & 15/16 (94) & $12 / 12(100)$ & $5 / 10(50)$ \\
\hline Spindle cell predominant & $8 / 16(50)$ & $3 / 12(25)$ & $9 / 10(90)$ \\
\hline Epithelioid cell predominant & $8 / 16(50)$ & $9 / 12(75)$ & $1 / 10(10)$ \\
\hline Loss of cellular cohesion & $1 / 16(6)$ & $0 / 12(0)$ & $0 / 10(0)$ \\
\hline Deep extension into subcutaneous tissue & $0 / 16(0)$ & $0 / 12(0)$ & $6 / 10(60)$ \\
\hline Lack of maturation & $1 / 16(6)$ & $0 / 12(0)$ & 9/10 (90) \\
\hline Ulceration & $0 / 16(0)$ & $0 / 12(0)$ & $0 / 10(0)$ \\
\hline Necrosis & $0 / 16(0)$ & $0 / 12(0)$ & $1 / 10(10)$ \\
\hline Inflammatory infiltrate $(++$ and +++$)$ & $1 / 16(6)$ & $1 / 12(8)$ & $4 / 10(40)$ \\
\hline Fibroplasia & $6 / 16(38)$ & $10 / 12(84)$ & $3 / 10(30)$ \\
\hline Nuclear pleomorphism & $7 / 16(44)$ & $8 / 12(67)$ & $8 / 10(80)$ \\
\hline Variation in nuclear chromatin & $1 / 16(6)$ & $3 / 12(25)$ & $3 / 10(30)$ \\
\hline Nuclear enlargement & $8 / 16(50)$ & $5 / 12(42)$ & $8 / 10(80)$ \\
\hline Variation in nucleoli & $7 / 16(44)$ & $3 / 12(25)$ & $4 / 10(40)$ \\
\hline Mitotic figures per 10 high-power fields & $12 / 16(75)$ & $5 / 12(42)$ & $9 / 10(90)$ \\
\hline Atypical mitotic figures & 10/16 (63) & 4/12 (33) & 9/10 (90) \\
\hline Marginal mitotic figures & $0 / 16(0)$ & $0 / 12(0)$ & $3 / 10(30)$ \\
\hline
\end{tabular}

(Figure 4). Some overlap was again seen in the distributions of p21 expression between Spitz nevi and melanoma.

We used a ROC curve to further examine the relationship between sensitivity and specificity of p21 positivity for predicting Spitzoid tumor type. This analysis indicated that nuclear p21 positivity was good at discriminating the Spitzoid category (Area under the curve $=0.89$, see Figure 5). Examination of the coordinate points on the curve was performed to determine the optimal sensitivity and specificity cut-off value. When nuclear p21 positivity was greater than $29 \%$, p 21 had $82 \%$ sensitivity and $81 \%$ specificity in predicting a tumor to be in the Spitzoid category. Finally, there was statistically significant and progressively stronger fatty acid synthase expression from nevi to malignant melanoma (Figure 6).

\section{Discussion}

The histologic features of Spitz nevi in the children and adults have not been compared in detail. ${ }^{27,28} \mathrm{We}$ found a significantly greater number of the intradermal lesions and increased dermal fibroplasia in adult specimens, but there were no other statistically significant differences between the age groups. Atypical mitotic figures were frequently seen in typical Spitz nevi in both children and adults and were not limited to atypical Spitz nevi.
Fatty acid synthase (EC 2.3.1.85) is a multifunctional enzyme, necessary of de novo synthesis of long-chain saturated fatty acids from acetyl-CoA, malonyl-CoA, and NADPH. Fatty acid synthesis appears to be a pivotal process required by many transformed cells for growth and survival. Recently, Innocenzi et $a l^{23}$ demonstrated statistical association of fatty acid synthase expression with Breslow thickness and overall survival in patients with malignant melanoma. All their metastatic melanomas showed strong fatty acid synthase expression, and we have seen similar results in our laboratory (unpublished data). In the study by Innocenzi et $a l^{23}$ all 30 conventional melanocytic nevi exhibited only weak fatty acid synthase expression-similar finding in our conventional melanocytic nevi. However, the expression of fatty acid synthase in Spitz nevi has not been previously reported. We observed a progressive increase in fatty acid synthase cytoplasmic expression with statistically significant differences observed between Spitz nevi and atypical Spitz nevi $(P=0.003)$ and between atypical Spitz nevi and malignant melanoma $(P<0.050)$. Fatty acid synthase expression may possibly have therapeutic relevance since inhibitors of fatty acid synthase, cerulenin and triclosan, have been shown to be cytotoxic to human cancer cells in vitro. ${ }^{29,30}$

We found that both typical and atypical Spitz nevi had significantly greater expression of p21 than conventional nevi and approached statistical significance for malignant melanomas, but overlaps in 

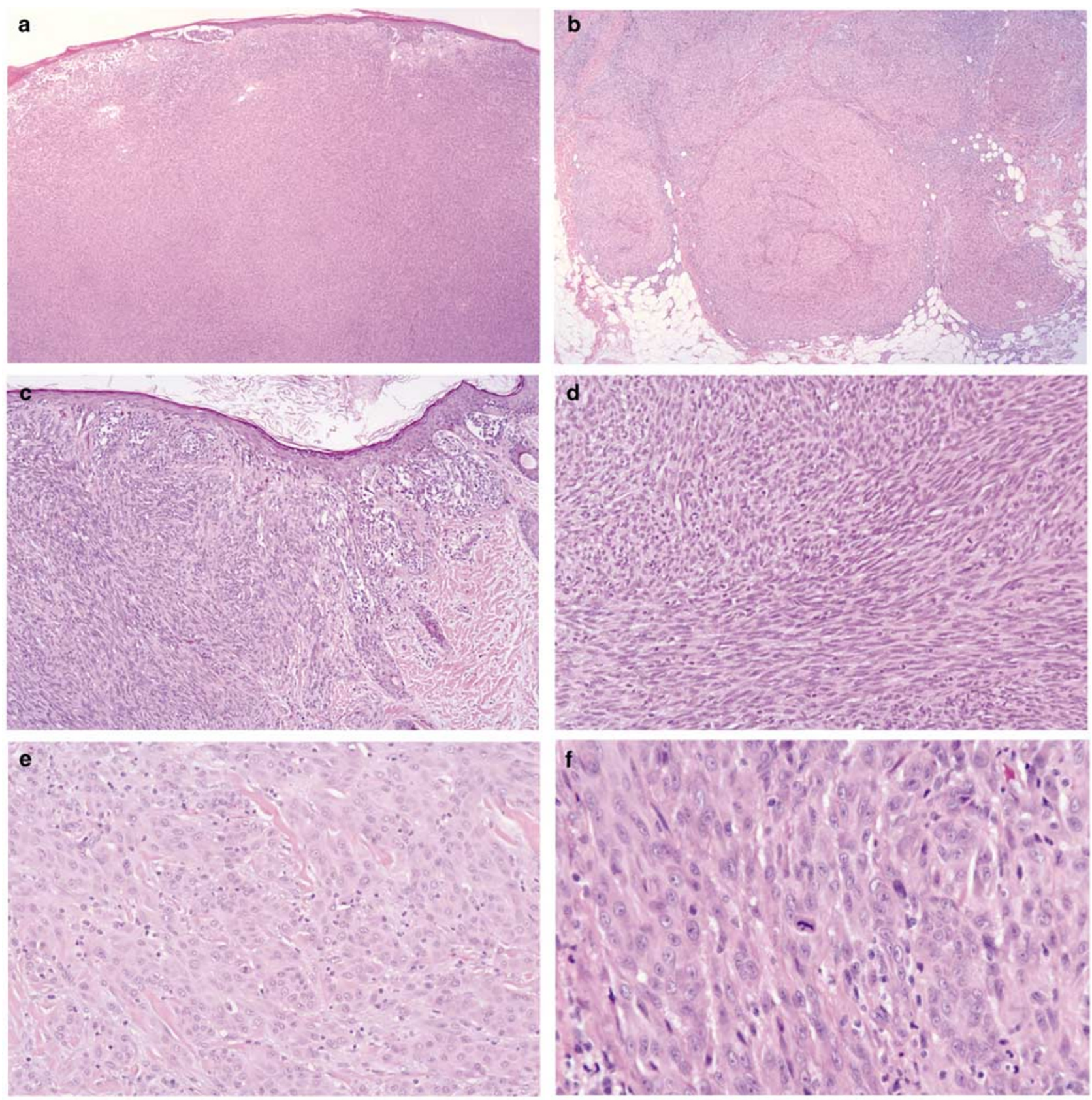

Figure 1 (a) An expansile nodular growth, (b) extension to the subcutaneous tissue and (c) lateral extension were seen in atypical pediatric Spitz nevi. (d) The predominant morphology was spindle but (e) epithelioid appearance was seen in one case. (f) Atypical mitotic figures were seen in the majority of cases.

Table 2 Summary of Ki-67, p21, and fatty acid synthase immunoreactivity

\begin{tabular}{|c|c|c|c|c|c|c|c|c|c|}
\hline & \multicolumn{3}{|c|}{ Ki-67 \% nuclear positivity } & \multicolumn{3}{|c|}{ p21\% nuclear positivity } & \multicolumn{3}{|c|}{ Fatty acid synthase (0-3+) positivity } \\
\hline & $N$ & Mean (s.d.) & $95 \% C I$ & $N$ & Mean (s.d.) & $95 \% C I$ & $N$ & Mean (s.d.) & $95 \% C I$ \\
\hline Conventional nevi & 19 & $0.53(0.61)$ & $0.23-0.82$ & 19 & $0.21(0.54)$ & $0.05-0.47$ & 19 & $0.21(0.42)$ & $0.01-0.41$ \\
\hline Spitz nevi & 26 & $5.04(2.46)$ & $4.05-6.03$ & 26 & $46.50(21.37)$ & $37.87-55.13$ & 26 & $0.46(0.65)$ & $0.20-0.72$ \\
\hline Atypical Spitz nevi & 10 & $10.0(4.16)$ & $7.02-12.98$ & 8 & $49.25(28.10)$ & $25.76-72.74$ & 8 & $1.56(0.73)$ & $1.00-2.11$ \\
\hline Malignant melanoma & 18 & $36.83(25.82)$ & $23.99-49.67$ & 18 & $27.50(18.03)$ & $18.53-36.57$ & 18 & $2.28(0.46)$ & $2.05-2.51$ \\
\hline
\end{tabular}

s.d.: standard deviation; CI: confidence interval. 

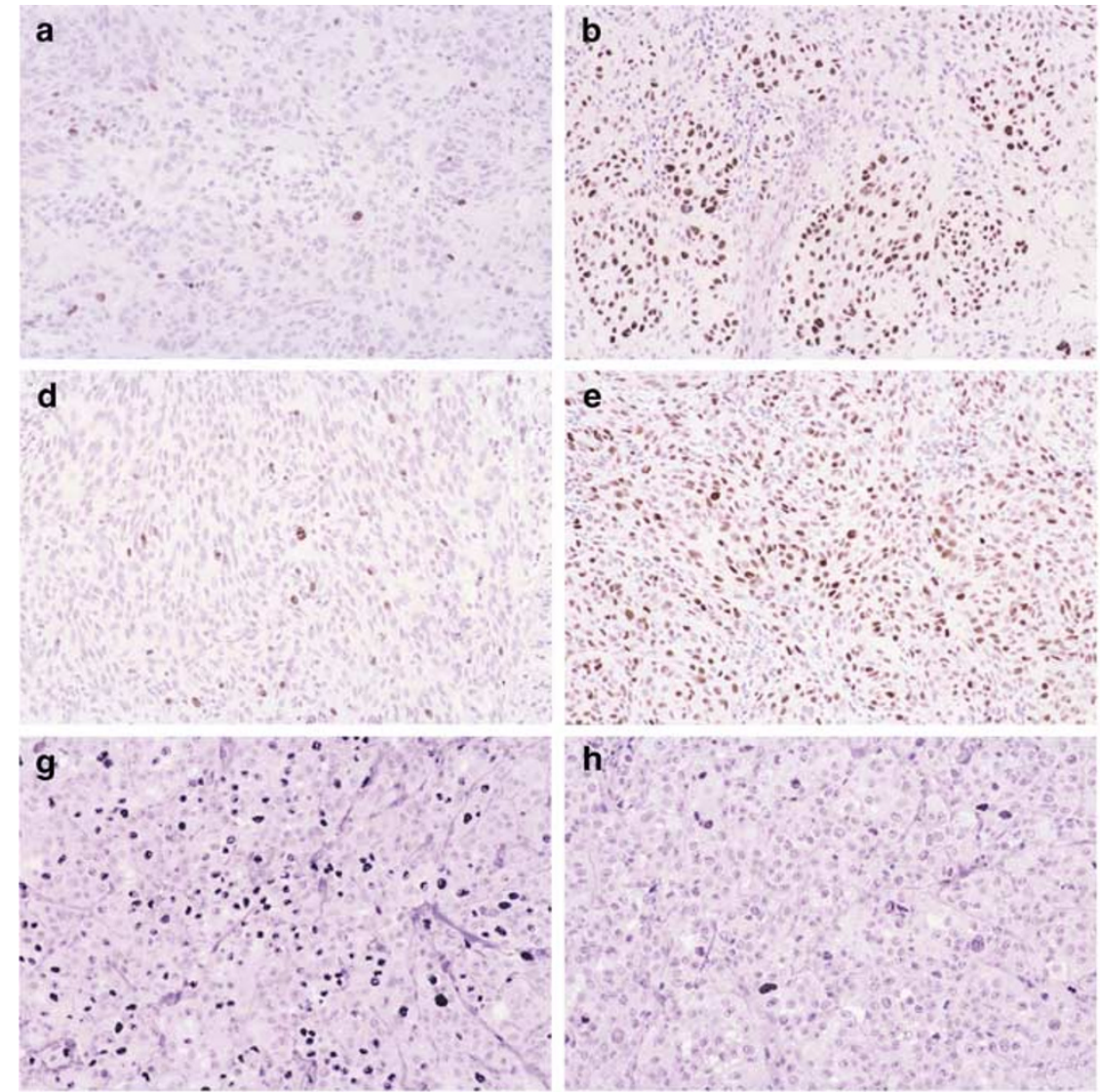
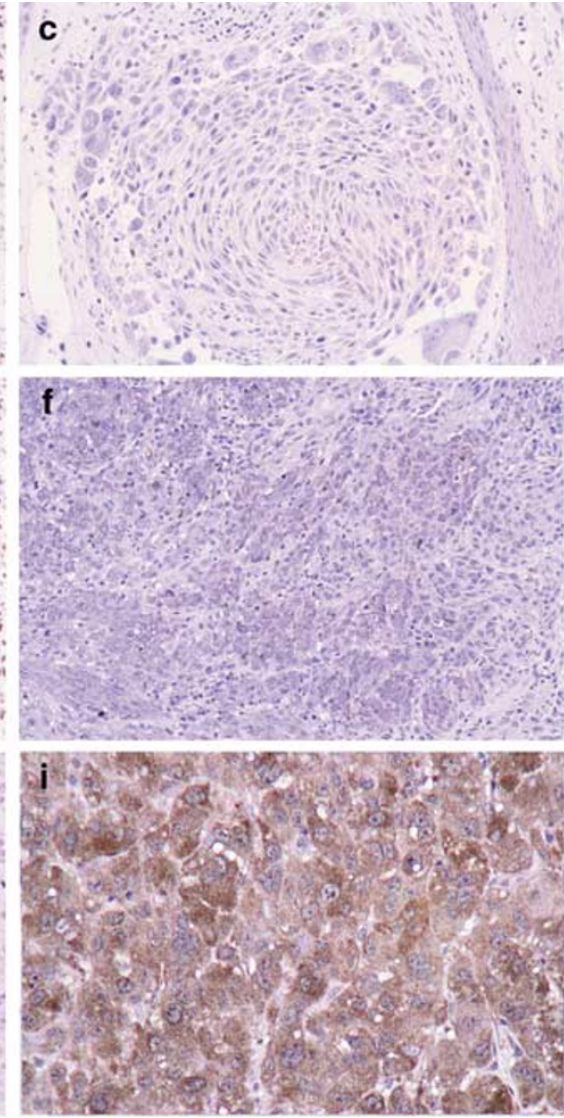

Figure 2 (a), (d), (g) Ki-67 immunoreactivity; (b), (e), (h) p21 expression; and (c), (f), (i) fatty acid synthase expression in typical Spitz nevus, atypical pediatric Spitz nevus, and malignant melanoma, respectively.

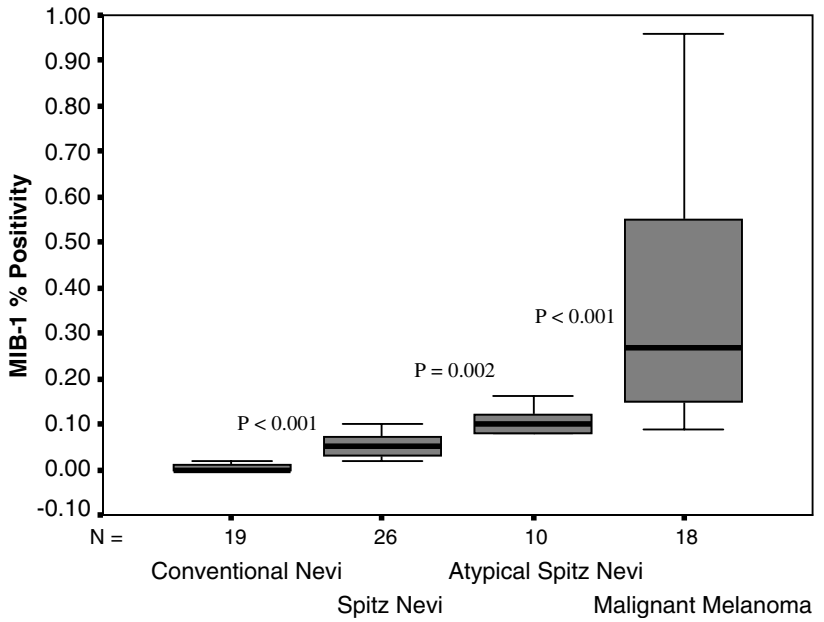

Figure 3 Box plot of the MIB-1 \% positivity. The box is limited by the 25th and 75th percentile and bar represents the median line. In addition, the lowest and highest values are outlined.

the distributions of p21 expression were also observed between the typical and atypical Spitz nevi and melanomas. Nonetheless, p21 expression was found to be both sensitive and specific for predicting Spitzoid category tumors. Recently, S100A6 protein expression was demonstrated to be

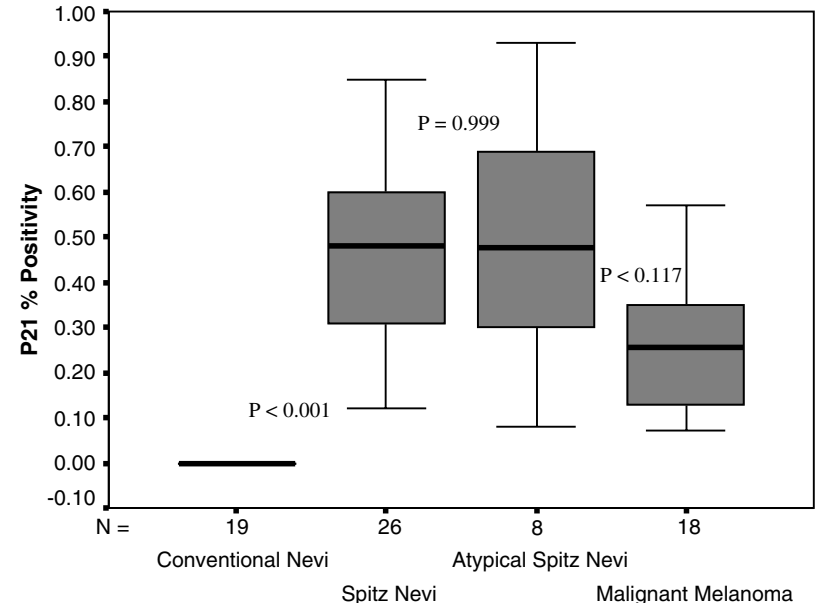

Figure 4 Box plot of the p21\% positivity.

significantly higher in Spitz nevi than in melanocytic nevi and malignant melanoma. ${ }^{31}$ Sprecher et $a^{32}$ found that Spitz nevi exhibited stronger Fas (CD95) expression than conventional nevi and malignant melanoma. In addition, Spitz nevi have molecular changes different from malignant melanoma such as 


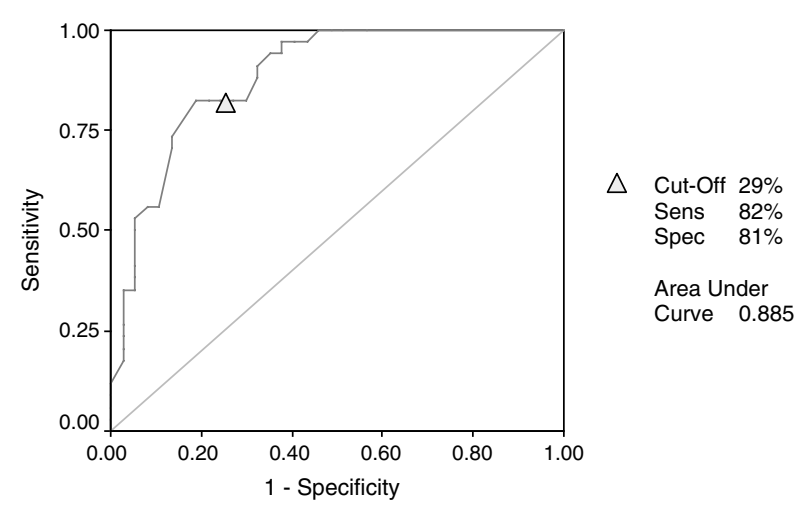

Figure 5 The receiver operating characteristic curve demonstrates the discriminating ability of p21 positivity.

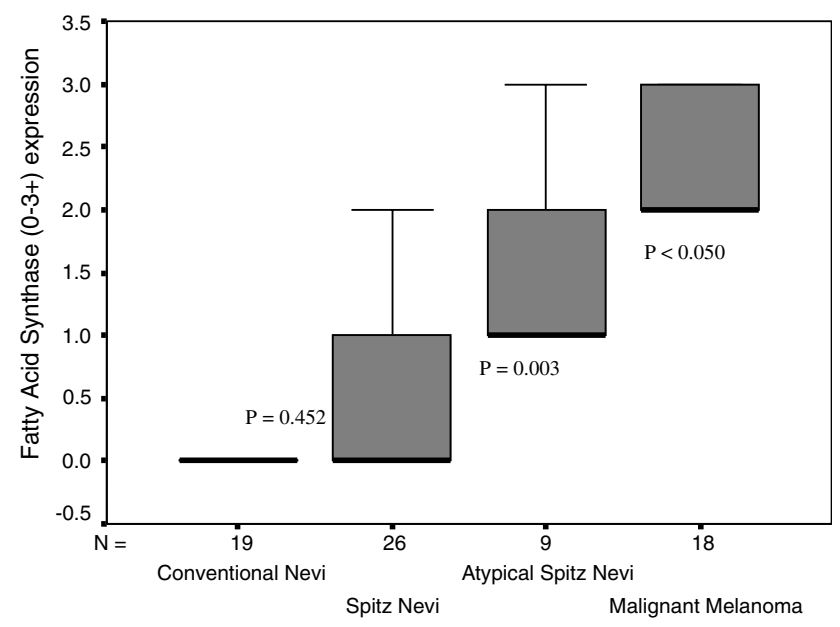

Figure 6 Box plot of fatty acid synthase expression.

H-ras gene amplification and the lack of T1796A mutation in the BRAF gene. ${ }^{33-35}$ These findings support the suggestion that Spitz nevus, in both its typical and atypical forms, is a distinct melanocytic neoplasm. p21 expression results in our study are in essential agreement with those previously reported. We found mean values of 46.50 and $49.25 \%$ in Spitz nevi and atypical pediatric Spitz nevi, respectively (Table 2). Similarly, Maldonado et al ${ }^{36}$ reported an average p21 expression of 45 and 39\% in Spitz nevi with and without $11 \mathrm{p}$ copy number increase, respectively. Trotter et $a l^{37}$ found mean of $29 \%$ in primary melanomas and $33 \%$ in metastatic melanoma; and the mean of $27.50 \%$ was seen in our melanoma cases (Table 2). The mean p21 expression was not calculated in studies by Karjalainen et $a 1^{38}$ and Sparrow et al; ${ }^{20}$ therefore, comparison cannot be made.

Transcription of the WAF1 gene under the control of p53 encodes the $\mathrm{p} 21^{\mathrm{WAF} 1 / \mathrm{CIP} 1}$ protein, which inhibits progression of the cell cycle at the G1-G2 phase. ${ }^{39} \mathrm{~A}$ number of cell cycle regulatory proteins that control G1/S transition including cyclin D1, cyclin D3, cyclin E, CDK2, p16 ${ }^{\mathrm{INK} 4 \mathrm{a}}, \mathrm{p} 27^{\mathrm{KIP} 1}$, and p21 $1^{\mathrm{WAF} 1 / \mathrm{CIP} 1}$ are deregulated in melanoma progression. ${ }^{40}$ Spitz nevi also display evidence of cell cycle deregulation such as increased cyclin D1, p21, p16, p27, and phospho-ERK expression, which may partly account for the overlapping immunoprofile seen in Spitz nevi and malignant melanoma. ${ }^{16,36}$ The adverse biologic effect of p21 and cyclin D1 overexpression in Spitz nevi might be mitigated by other properly functioning G1 regulatory mechanisms still present in Spitz nevi, but lost in malignant melanoma.

A number of investigators have suggested a role for MIB-1 immunostaining as a diagnostic adjunct for distinguishing Spitz nevus from malignant melanoma. ${ }^{16,17,22,41}$ Nagasaka et $a l^{16}$ found that all Spitz nevi had a relatively low MIB-1 index (mean $3.2 \%$ ), which was significantly lower than that of malignant melanoma (mean 15.3\%). Similarly, Kanter-Lewensohn et $a l^{17}$ found an average MIB-1 index of $4 \%$ in Spitz nevi and $29.7 \%$ in malignant melanoma and Bergman et $a l^{22}$ reported $1.5 \%$ for Spitz nevi vs $14.9 \%$ for malignant melanoma. Our data are consistent with these prior observations (Table 1).

In summary, our findings support the premise that atypical Spitz nevi are lesions of borderline biologic behavior lying between Spitz nevi and malignant melanoma, as evidenced by Ki-67 and fatty acid synthase expression that is intermediate yet statistically different from both. In addition, typical and atypical Spitz nevi both have similarly high p21 expression yet display lower Ki-67 and fatty acid synthase immunoreactivity than malignant melanomas. Thus, a lesion with high p21 expression and low Ki-67 and fatty acid synthase activity is more likely to be an atypical Spitz nevus than a malignant melanoma.

\section{Acknowledgements}

We thank James L Burchette and Dinesh Rakheja for their technical assistance.

\section{References}

1 Spitz S. Melanomas of childhood. Am J Pathol 1948;24:591-609.

2 Farmer ER, Gonin R, Hanna MP. Discordance in the histopathologic diagnosis of melanoma and melanocytic nevi between expert pathologists. Hum Pathol 1996;27:528-531.

3 Barnhill RL, Argenyi ZB, From L, et al. Atypical Spitz nevi/tumors: lack of consensus for diagnosis, discrimination from melanoma, and prediction of outcome. Hum Pathol 1999;30:513-520.

4 Barnhill RL, Flotte TJ, Fleischli M, et al. Cutaneous melanoma and atypical Spitz tumors in childhood. Cancer 1995;76:1833-1845.

5 Spatz A, Calonje E, Handfield-Jones S, et al. Spitz tumors in children: a grading system for risk stratification. Arch Dermatol 1999;135:282-285. 
6 Walsh N, Crotty K, Palmer A, et al. Spitz nevus versus spitzoid malignant melanoma: an evaluation of the current distinguishing histopathologic criteria. Hum Pathol 1998;29:1105-1112.

7 Bergman R, Dromi R, Trau H, et al. The pattern of HMB-45 antibody staining in compound Spitz nevi. Am J Dermatopathol 1995;17:542-546.

8 Palazzo J, Duray PH. Typical, dysplastic, congenital, and Spitz nevi: a comparative immunohistochemical study. Hum Pathol 1989;20:341-346.

9 Smith KJ, Barrett TL, Skelton HG, et al. Spindle and epithelioid cell nevi with atypia and metastasis (malignant Spitz nevus). Am J Surg Pathol 1989; 13:931-939.

10 Howat AJ, Giri DD, Cotton DWK, et al. Nucleolar organizer regions in Spitz nevi and malignant melanomas. Cancer 1989;63:474-478.

11 Penneys NN, Seigried E, Nahass G, et al. Expression of proliferation cell nuclear antigen in Spitz nevi. J Am Acad Dermatol 1995;32:954-967.

$12 \mathrm{Tu}$ P, Miyauchi S, Miki Y. Proliferative activities in Spitz nevus compared with melanocytic nevus and malignant melanoma using expression of PCNA/cyclin and mitotic rate. Am J Dermatopathol 1993;15: 311-314.

13 Bergman R, Kerner H, Manov L, et al. C-fos protein expression in Spitz nevi, common melanocytic nevi, and malignant melanomas. Am J Dermatopathol 1998;20:262-265.

14 Bergman R, Lurie M, Kerner H, et al. Mode of c-myc protein expression in Spitz nevi, common melanocytic nevi and malignant melanomas. J Cutan Pathol 1997;24:219-222.

15 Guttman-Yassky E, Bergman R, Manov L, et al. Human telomerase RNA component expression in Spitz nevi, common melanocytic nevi, and malignant melanomas. J Cutan Pathol 2002;29:341-346.

16 Nagasaka T, Lai R, Meideros LJ, et al. Cyclin D1 overexpression in Spitz nevi: an immunohistochemical study. Am J Dermatopathol 1999;21:115-120.

17 Kanter-Lewensohn L, Hedblad MA, Weide J, et al. Immunohistochemical markers for distinguishing Spitz nevi from malignant melanomas. Mod Pathol 1997;10:917-920.

18 Kaleem Z, Lind AC, Humphrey PA, et al. Concurrent Ki-67 and p53 immunolabeling in cutaneous melanocytic neoplasms: an adjunct for recognition of the vertical growth phase in malignant melanomas? Mod Pathol 2000;13:217-222.

19 Bergman R, Shemer A, Rivka L, et al. Immunohistochemical study of p53 protein expression in Spitz nevi as compared with other melanocytic lesions. Am J Dermatopathol 1995;17:547-550.

20 Sparrow LE, Eldon MJ, Engligh DR, et al. P16 and p21WAF1 protein expression in melanocytic tumors by immunohistochemistry. Am J Dermatopathol 1998; 20:255-261.

21 Gerdes J, Lemke H, Baisch H, et al. Cell cycle analysis of a cell proliferation-associated human nuclear antigen defined by the monoclonal antibody Ki-67. J Immunol 1984;133:1710-1715.

22 Bergman R, Malkin L, Sabo E, et al. MIB-1 monoclonal antibody to determine proliferative activity of Ki-67 antigen as an adjunct to the histopathologic differential diagnosis of Spitz nevi. J Am Acad Dermatol 2001;44:500-504.
23 Innocenzi D, Alo PL, Balzani A, et al. Fatty acid synthase expression in melanoma. J Cutan Pathol 2003;30:23-28.

24 Barnhill RL. Pathology of Melanocytic Nevi and Malignant Melanoma. Butterworth-Heinemann: Boston, MA, 1995, p. 110.

25 Uchiyama N, Yamamoto A, Kameda $\mathrm{K}$, et al. The activity of fatty acid synthase of epidermal keratinocytes is regulated in the lower stratum spinulosum and the stratum basale by local inflammation rather than by circulating hormones. J Dermatol Sci 2000;24: 134-141.

26 Kamino H, Tam ST. Immunoperoxidase technique modified by counterstain with azure B as a diagnostic aid in evaluating heavily pigmented melanocytic neoplasms. J Cutan Pathol 1991;18:436-439.

27 Echevarria R, Ackerman LV. Spindle and epithelioid cell nevi in the adult: clinicopathological report of 26 cases. Cancer 1967;20:175-189.

28 Weedon D, Little JH. Spindle and epithelioid cell nevi in children and adults: a review of 211 cases of the Spitz nevus. Cancer 1977;40:217-225.

29 Kuhajda FP, Pizer ES, Li JN, et al. Synthesis and antitumor activity of an inhibitor of fatty acid synthase. Proc Natl Acad Sci USA 2000;97:3450-3454.

30 Kuhajda FP. Fatty acid synthase and human cancer: new perspectives on its role in tumor biology. Nutrition 2000;16:202-208.

31 Ribe A, McNutt NS. S100A6 protein expression is different in Spitz nevi and melanomas. Mod Pathol 2003;16:505-511.

32 Sprecher E, Bergman R, Meilick A, et al. Apoptosis, Fas and Fas-ligand expression in melanocytic tumors. J Cutan Pathol 1999;26:72-77.

33 Bastian BC, LeBoit PE, Pinkel D. Mutations and copy number increase of HRAS in Spitz nevi with distinctive histopathologic features. Am J Pathol 2000;157: 967-972.

34 Palmedo G, Hantschke M, Rutten A, et al. The T1796A mutation of the BRAF gene is absent in Spitz nevi. J Cutan Pathol 2004;31:266-270.

35 Yazdi AS, Palmedo G, Flaig MJ, et al. Mutations of the $B R A F$ gene in benign and malignant melanocytic lesions. J Invest Dermatol 2003;121:1160-1162.

36 Maldonado JL, Timmerman L, Fridlyand J, et al. Mechanisms of cell-cycle arrest in Spitz nevi with constitutive activation of the MAP-kinase pathway. Am J Pathol 2004;164:1783-1787.

37 Trotter MJ, Tang L, Tron VA. Overexpression of the cyclin-dependent kinase inhibitor p21 (WAF1/CIP1) in human cutaneous malignant melanoma. J Cutan Pathol 1997;24:265-271.

38 Karjalainen JM, Eskelinen MJ, Kellokoski JK, et al. P21 ${ }^{\text {WAF1/CIP1 }}$ expression in stage I cutaneous malignant melanoma: its relationship with p53, cell proliferation and survival. Br J Cancer 1999;79:895-902.

39 Xiong Y, Hannon GJ, Zhang H, et al. p21 is a universal inhibitor of cyclin kinases. Nature 1993;366:701-704.

40 Alonso SR, Ortiz P, Pollan M, et al. Progression in cutaneous malignant melanoma is associated with distinct expression profile. Am J Pathol 2004;164: 193-203.

$41 \mathrm{Li}$ LX, Crotty KA, McCarthy SW, et al. A zonal comparison of MIB1-Ki67 immunoreactivity in benign and malignant melanocytic lesions. Am J Dermatopathol 2000;22:489-495. 